\title{
ENERGY CONSUMPTION METHODS, CO2 EMISSIONS AND DRIVING CYCLES FOR AUTOMOTIVE VEHICLES: BRIEF REVIEW
}

\author{
Sandro Guerreiro Ferreira Neves ${ }^{a}$, PhD Lilian Lefol Nani Guarieiro ${ }^{a}$, PhD Gisele \\ Olímpio da Rocha ${ }^{a}$, Allison Amorim do Nascimento ${ }^{a}$
a Professional Masters in Sustainable Development Centro Universitário SENAI CIMATEC, Brazil

\begin{abstract}
The energy consumption of automotive vehicles has been the subject of major discussions worldwide, mainly with the fomentation to introduce electric vehicles in replacement of vehicles powered by fossil and renewable fuels. The main goal of this study was to perform a systematic review on the available literature for calculating energy consumption regardless of the source consumed: fossil, renewable or electric sourcing. Additionally, we also focused on understanding methods for measuring $\mathrm{CO} 2$ emissions and review the main automotive driving cycles globally. More recently published studies were visited in order to formulate a theoretical basis on the aforementioned topic. The proposal intended to clarify and support projects in the development mobility field and serve as a model for referenced research for energy consumption of automotive vehicles.
\end{abstract}

Keywords: Energy consumption; vehicles; driving cycles; fuels; mobility.

\section{MÉTODOS DE CONSUMO DE ENERGIA, EMISSÕES DE CO2 E CICLOS DE CONDUÇÃO PARA VEÍCULOS AUTOMOTIVOS: UMA BREVE REVISÃO}

Resumo: O consumo energético de veículos automotivos vem sendo pauta de grandes discussões no cenário mundial, principalmente com o fomento para introdução de veículos elétricos em substituição de veículos movidos a combustível fóssil e renováveis. O Objetivo deste trabalho foi realizar uma revisão sistemática da literatura disponível para cálculo de consumo energético independentemente da fonte consumida: fossíl, renovável ou elétrica. Adicionalmente, nós focamos em entender métodos para mensurar emissão de $\mathrm{CO} 2$ e revisar os principais ciclos de condução automotivos existentes no cenário mundial. Foram visitadas publicações e artigos mais recentes do tema para formular uma base teórica sobre o tema supracitado. A proposta teve como intenção esclarecer e apoiar projetos na área de desenvolvimento da mobilidade e servir de modelo para pesquisas referenciadas para consumo energético de veículos automotivos.

Palavras-chave: Consumo energético; veículos; ciclos de condução; combustíveis; mobilidade. 


\section{INTRODUCTION}

There is a growing need for searching for alternative energies to maintenance and preservation of the environment. Following this model, the authorities and governments are concerned with Greenhouse gases emissions and effects on the environment. According the data from International Energy Agency (IEA), the transport sector is the fourth main contributor of $\mathrm{CO}_{2}$ emissions around the world. For instance, this can be observed in a study which accounted for CO2 emission by sector from 1990 through 2017 [1]. This data is very important to understand where should be directed efforts to improve and reduce $\mathrm{CO} 2$ emissions.

The major contributor for $\mathrm{CO} 2$ emissions demand related transport sector are passenger vehicles and the estimative for energy consumption in this segment will be approximately more than $40 \%$ of all energy until 2050. Another important and impressive number will be the projection of vehicles on roads around the world up to 2050 , the low level estimate is around 3 billion vehicles [3,5]. The Brazilian reality is similar to the rest of the world, following the same comparison parameters. At Brazil, replacing the INOVAR AUTO, Brazilian Program for automotive vehicles related emissions rules, finished on December 2017, Federal Government create a new program denominated ROTA 2030. The main objective is develop the automotive sector and this project had the final approval on MP 843/2018 (Nov 2018). ROTA 2030 define progressively emissions reduction to be attended by Automotive Companies, that will be benefit with tax reductions and Brazil confirmed the Paris Agreement assuming to reduce emissions progressively until $2030[2,6]$. The insertion for the new Program aims to increase and incentive Companies to invest on research, technology development and have as main principles environmental sustainability and citizenship. This project is very aligned with the Agenda for Sustainable Development that includes 17 Sustainable Development Goals leaded by United Nations [7].

This paper propose understand several methods to analyze energy consumption, showing details about region applications, revise the methods applicable for automotive vehicles and raise a reflection of community about the impacts for consumption, for emissions and for the world. This brief literature review report the energy consumption and emissions within the transportation sector as well as to address the driving cycles most used which define the calculation parameters for all automotive industries, to collaborate with Government deciding goals and strategies to reduce polluting gases issues and orientate customers about expectative for them vehicles, showing the reality and transparency data. Each market demands requirements for attending the targets and goals imposed by each country's Government. Each emission method have specific strategy to calculate but all of them have the same proposal: Elaborate, define, calculate and share for interested parts, real data about automotive vehicles and transportation in general. This paper works as a theoretical basis for new studies on the driving cycles theme adding value to expand the mobility projects. CO2 emission impacts caused by transportation are discussed to better support its understanding. Program emissions help to direct and determine rules to be followed by companies and currently it is separated by phases to implement gradually.

\section{METHODOLOGY}

The main goal for this article was supplying what is known regarding harmful gases, greenhouse gas, carbon dioxide emissions and energy consumption originated from automotive vehicles and other transportation modes, considering the driving 
cycles used. Several articles, theses and periodicals were revised to raise technical material about the topic. The material selected were searched on CAPES Periodicals www.capes.gov.br/" www.capes.gov.br/ (Coordination for the Improvement of Higher Education Personnel), Google Scholar scholar.google.com.br" www.scholar.google.com.br, Science Direct https://www. sciencedirect.com/" https://www. sciencedirect.com/, Science https://www.sciencemag.org/" https://www.sciencemag.org/, SAE https://www.sae.org/" https://www.sae.org/ (Society of Auto- motive Engineers), NBR http://www.abnt.org.br/normalizacao/abnt-catalogo" http://www.abnt.org.br/normalizacao/abnt-catalogo and Scielo https://scielo.org/" https://scielo.org/ (Scientific Electronic Library Online).

The keywords (energy consumption, vehicles, driving cycles, fuel and mobility) were used to research the articles considering the last 10 years (2010-2020) by each keyword considered according the table 1 showed below. The focal point is searching data by keywords launched in the periodicals which have information about multiple themes, not only directly linked with the proposed topic in the present manuscript. Other searches were based on current applications for electric automotive vehicles due to the large tendency to replace fossil fuel-based vehicles. Based on the quantity of data found, we can conclude a high relevance around this subject and the scientists concern to reduce $\mathrm{CO} 2$ emissions, improve energy consumption for vehicles and different transport mode.

Table 1: Number of searches by keyword vs scientific periodicals.

\begin{tabular}{|c|c|c|c|c|c|}
\hline & Scielo & CAPES & $\begin{array}{c}\text { Google } \\
\text { Academic }\end{array}$ & Science & $\begin{array}{c}\text { Science } \\
\text { Direct }\end{array}$ \\
\hline Energy Consumption & 1,677 & 33 & $1,980,000$ & 320 & 488,336 \\
\hline Vehicles & 938 & 39 & $1,880,000$ & 962 & 431,834 \\
\hline Driving Cycles & 12 & 0 & 17,900 & 4 & 178,919 \\
\hline Fuel & 1,374 & 14 & $1,860,000$ & 2,710 & 490,623 \\
\hline Mobility & 3,401 & 50 & $1,660,000$ & 2,494 & 405,259 \\
\hline
\end{tabular}

\section{RESULTS AND DISCUSSION}

\subsection{Energy Consumption Models and $\mathrm{CO} 2$ emissions}

There are several emission calculation methodologies available. In the next section, it will present 7 methods have been raised due to relevance and most searched and used. Literature is available and some periodicals were published base on them. These methods have different calculation methods but all of them have the same objective, elaborate data for emissions, providing the government delineate the strategies for each country.

\subsubsection{Top-Down Model}

The top-down model was developed by Intergovernmental Panel on Climate Change (IPCC) aligned with United Nations Organization (ONU) [4]. This method is easier to calculate because it needs a reduced quantity of data available for its application and use [9-14]. Top down Method is based apparent consumption of the country. The Top Down methodology is based on CO2 emissions, using energy production and consumption data as a calculation regardless of the source consumed (fossil, electric, others) (Table 2). Also, Top down method is descripted 6 steps to calculate CO2 emissions [9-16]. 
Table 2. Steps to calculate CO2 emissions

\begin{tabular}{|c|c|c|}
\hline \# & Description & Equation \\
\hline Step 1 & Calculation of Energy Consumption (CC) & $C C=C A \times F_{\text {conv }} \times 45,2 \times 10^{-3} \times F_{\text {corr }}$ \\
\hline Step 2 & Calculation of Carbon Amount & $Q C=C C \times F_{\text {emiss }} \times 10^{-3}$ \\
\hline Step 3 & Calculation of the Quantity of Fixed Carbon (QCF) & $Q C F=Q C \times F C F_{i x}$ \\
\hline Step 4 & Calculation of Liquid Carbon Emissions (ELC) & $E L C=Q C-Q C F$ \\
\hline Step 5 & Calculation of Real Carbon Emissions (ERC) & $E R C=E L C \times F C O$ \\
\hline Step 6 & Calculation of Actual $\mathrm{CO} 2$ Emissions (ERCO2) & $E R C O 2=E R C \times[44 / 12]^{*}$ \\
\hline \multicolumn{3}{|c|}{$\begin{array}{l}\text { Nomenclature: } \mathrm{CA}=\text { Apparent Fuel Consumption } / \mathrm{F}_{\mathrm{conv}}=\text { depends fuel used } / \mathrm{F}_{\mathrm{corr}}=\text { depends of } \\
\text { chemical phase of fuel utilized } / \mathrm{F}_{\mathrm{emiss}}=\text { Carbon Emission Factor } / \mathrm{FCF}_{\mathrm{ix}}=\mathrm{Fixed} \text { Carbon Fraction } / \\
\mathbf{4 4 / 1 2 ^ { \star }}=\text { ratio of the molecular weight of carbon dioxide and carbon. }\end{array}$} \\
\hline
\end{tabular}

\subsubsection{Bottom-Up Model}

Following the structure from Top-Down, the Bottom-up also was developed by Intergovernmental Panel on Climate Change (IPCC) aligned with United Nations Organization [4]. This is considered as a complementary model of the Top-down method because it uses more data to calculate and there is a detailed description. Top Down method requires more details and due to complexity to collect data by studied sector, it is more expensive related costs. This method considers in the study the place and region, the driving technology, mileage, the emission data obtained from the laboratory, consumption, the fuel quality and the motor technology [8-14]. The equation 1 shows one application for Bottom up model. The major advantage from Bottom-up model is the calculation considers other gases besides $\mathrm{CO} 2$ (for example $\mathrm{CO}, \mathrm{NOx}$, $\mathrm{CH} 4$, mainly the greenhouse gases).

$$
\text { Emissions }_{i}=F E_{i a b c} \times \text { Energy }_{a b c}
$$

Where Emissions = emissions from a specific gas, $\mathrm{FE}=$ emissions factor, Energy = energy consumed per distance, $\mathrm{i}=$ gas selected $(\mathrm{CO} 2, \mathrm{CO}, \mathrm{NOx}, \mathrm{CH} 4$, etc.), $\mathrm{a}=$ fuel selected, $\mathrm{b}=$ vehicle type and $\mathrm{c}=$ emission control. The process to raise date to calculation requires some information about vehicles in study and technical knowledge for fuel and emissions.

\subsubsection{NTM Model}

NTM means Network for Transport and Environment and it was created on Sweden. Its proposal is to calculate the emissions impacts of several transportation modes (sea, road, tail, air) $[13,16,17]$. The NTM model provides high quality data about emissions for both passenger and freight vehicles. This database contained energy consumption and emission factors to support the calculating methodology. The service is web-based, which links algorithms and databases, with inputs from users. The results are calculated greenhouse gas emissions and energy consumption $[13,16,17]$.

NTM model is considered a complete method due to the quantity of variables included in the study as vehicle type, vehicle segment, fuel, cargo type, passenger load, traffic situation, emission standard fuel consumption, distance, road gradient, vehicle load capacity, cargo load factor and cargo weight. Users of the NTM model have the possibility of specifying some parameters, such as vehicle type, vehicle segment, among others. These variables contain rich information and collaborate to turn NTM model as robust method. Each variable can influence consumption conditions and gas emissions. 
Another important aspect of this method is how much details could be added in the study. Regarding NTM model detailing, there are at least 3 levels of them descripted. In these levels, the data complexity (or completeness) increase gradually from the level \#1 through level \#3 [16]. The level 1 is average vehicle age, Engine type, Fuel type and Average vehicle load. Level 2 is Vehicle type, Average engine age, Average load vehicle capacity and level 3 is Calculation of the carbon dioxide emission for each type of vehicle.

Each step define one level of difficulty and add information for the method. NTM method may be applied for different transport modes, such as roads, rail, water way and air and it have a good application for $\mathrm{CO} 2$ emissions. In addition, it may also obtain emission results for $\mathrm{SO} 2 \mathrm{NOx}, \mathrm{N} 2 \mathrm{O}, \mathrm{CH} 4$, hydrocarbons (includes $\mathrm{CH} 4$ ), and others.

\subsubsection{STREAM}

STREAM means Study on Transport Emissions of all Modes, originated from Netherlands. The model is a partnership proposal between CE Delft and RIVM (Dutch National Institute of Public Health and Environment), with the intention of study about all modes of transport $[16,18]$. The main focus of the study is emissions of the greenhouse gases, $\mathrm{CO} 2$, and other air pollutants. Logistical factors such as vehicle occupancy (amount of people) and loading factors (vehicle with or w/o load) are relevant information for the Stream model.

Stream Model considers emissions rates lower for vehicle younger compared with older due to development of new technology. In the calculation method considers, emissions for transport, the fuel, number de person per vehicle, transportation mode, emissions for ton or $\mathrm{km}$, etc. Based on this, this model consists in calculate the entire emission chain. $[16,18]$. This model cover transport for roads, rail, sea and air.

\subsubsection{EcoTransIT}

EcoTrans IT means Ecological Transport Information Tool and it was developed by IFEU - Institut für Energie- und Umweltforschung in association with railway Companies. IFEU conducts research and provides a worldwide consultancy service in relation to all major environmental and sustainability issues $[16,19,20]$. The data are aligned and harmonized with the NTM Model. EcoTransIT calculates transport distances, energy consumption, greenhouse gases $\mathrm{CO} 2$ and $\mathrm{CO} 2$ equivalents. In addition, it also considers SOx, NOx, NMHC and PM10 air pollutants for any global transport chain, considering loads for vehicles by land, water and air.

This model calculates the emission of carbon dioxide using several factors, such as loads and types of vehicles $[16,19,20]$. This method is a powered tool and consider several factors (distance, vehicle type, gas emission, country, transportation mode, freight mode, fuel type, etc.). The IFEU study is completely available at their website, but documentation record is available only on Dutch language. Web-based simulation is opened for the public and anyone is able to simulate several conditions of transportation.

\subsubsection{ARTEMIS}

The term ARTEMIS stands for Assessment and Reliability of Transport Emission Modelling and Inventory Systems. It was developed for all types of transportation. It was created with several partners and funded by European Union $[16,21]$. This model has been developed to calculate emission for each country due to 
number of variables and parameter included in the study. The calculations by this method have an enormous level of detail comparing to other methods. Artemis uses rural and urban topology, this method calculation as well as considers the type of traffic used, fuel quality, and different emission concepts. The basics principles are based on the observation of the vehicle used and the operating conditions in real world, description of driving conditions, description of vehicle used and the development of representative driving cycles. Another relevant point is Artemis has elaborated its own driving cycle.

\subsubsection{GHG Protocol}

The GHG Protocol is Greenhouse Gases Protocol, it is an initiative of several working groups around the world for Sustainable Development. It is a tool used to understand, quantify and manage GHG emissions. It is originated in the USA (1998), done by the World Resources Institute (WRI). This model is currently the most used method worldwide by companies and governments for carrying out GHG inventories. In Brazil, this protocol was started in 2007, in association with the Ministry of the Environment, the Foundation Getulio Vargas Sustainability Study Center - GVces, and WRI. It is compatible with ISO 14.064 and is aligned with the Intergovernmental Panel on Climate Change (IPCC). [16,23,24]. The GHC Protocol is based on three scopes, as follow: (i) Direct GHG emissions - GHG emissions from sources that are owned or controlled by the Company; (ii) Electricity indirect GHG emissions - GHG emissions from the generation of purchased electricity consumed by the company; and (iii) Other indirect GHG emissions - GHG emissions from all other (indirect) activities, such as transport.

In case, a Company selects to report GHG emissions according the GHG Protocol, there are 3 scopes. Scope (i) and (ii) are mandatory and scope (iii) is not mandatory. The GHG Protocol in Brazil have a calculation tool updated annually to adapt to reality and needed according new publications and standards. Other important point is the annual report consolidating the public record of emissions for a specific region, industrial branch, etc. Both information are available in the GHG protocol site managed by Government and FGV. [16,23,24].

\subsection{Driving Cycles}

The best definition for driving cycle is a sequence of operating conditions (idle, acceleration, deceleration and cruise speed) used to represent a standard driving cycle, widely used in emissions testing. It will be present a brief for 4 driving cycles models. However, there are several models available and each government have a specific regulation adapted for the country strategy $[22,25,26]$.

The first is cycles Artemis drive cycle is based on statistical study made by 4 different configurations: urban cycle, rural cycle, highway at $130 \mathrm{~km} / \mathrm{h}$ and highway at $150 \mathrm{~km} / \mathrm{h}$. Second, FTP-75 - Federal test Procedure is represented by 2 stages: urban cycling including current interruptions and driving on highway roads. Third, NEDC - New European Driving Cycle is a reference for homologation in Europe attending Euro-6 regulations. Last one is WLTP - Worldwide Harmonized Light Vehicles Test procedure replaced the NEDC method and it is the new test procedure for light vehicles to measure fuel consumption and $\mathrm{CO} 2 /$ pollutant emissions. The main goal is to give to consumers more realistic data that reflects the daily vehicle use.

\subsection{Brazilian Conditions and Requirements}


At Brazil, the requirements consider some NBR's as regulation. They are the NBR 10312 (Coast down), NBR6601 (City cycle) and NBR7024 (Highway), including NBR 15567 complementing for hybrids vehicles [4]. Vehicle test specifications for dynamometers are determined by Brazilian regulations. These regulations include, as reference but not limited to, the vehicle displacement resistance and physical characteristics. . To collect these specifications, some parameter need to be known (weight, speed, vehicles characteristics) to be reproduced on dynamometer real situations. Exhaust gases are acquired and analyzed and, using a stoichiometric balance, then, determined Fuel consumption and Emissions. Brazil have several studies funded by Ministry of the Environmental and non-governmental partners to reinforce the commitment with Paris Agreement to reduce GHG emissions by $37 \%$ below 2005 levels in 2025 and consequently reduce GHG emissions by $43 \%$ below 2005 levels in 2030 [2].

Rota 2030 is a Federal Program for the automotive industry with the objective of supporting technological development, competitiveness, innovation, vehicle safety, environmental protection, energy efficiency and the quality of automobiles. This program bring a reduction of Income Tax, reduction of Import Tax and IPI reduction for Automotive Companies [12].

\section{CONCLUSION}

This paper review key information and present a brief literature available for Energy Consumption, $\mathrm{CO} 2$ emissions, Greenhouse gases, driving cycles and where the Brazil is inserted in this scenario. All data presented were searched in periodicals and official sites from Government, Institutions focused in Mobility Sustainable, which pursuit the 17 Objectives Sustainable Development. The main goal is orientate new researches on the subjects mentioned and supply knowledge guided for current process and regulations. Additionally, a deep search is needed to define the consumption and emissions for a region, country or global requirements. Companies are facing big challenges to meet all emissions requirements to turn the vehicle saleable for each region. In case, a vehicle not meet the limits determined for each phase, their commercialization is not allowed. One system of balanced mobility should be an important objective, mainly in the current fomentation to reduce gases emissions. The relevant point are all incentives from Government to meet solid results and the alternative use of hybrid and electric vehicles can be a solution to achieve the targets. The 3 points for electric vehicle are: First one is electric vehicles exhaust zero $\mathrm{CO}_{2}$ gases, but the sourcing to produce the energy necessary to function the vehicle bring a large impact for emissions, mainly in countries without resources of renewable energy as example, Europe; Second one is the high cost to implement as public transport and acquire as personal transport; And the third one is the way to discard the batteries after the cycle life and the raw material to produce, that also have a big impacts for environmental. This is one more challenge for scientists and development technology.

\section{REFERENCES}

${ }^{1}$ https://www.iea.org/data-and-statistics/?country=WORLD\&fuel=CO2\%20emissions\&indicator Accessed on July $11^{\text {th }} 2020$. Data and statistics (2017).

2 http://www.mctic.gov.br/mctic. Accessed on July $11^{\text {th }}$ 2020. Ministry of Science, Technology, Innovations and Communications - MCTIC (2020), Brazil's Third Biennial update report

${ }^{3}$ DOUCETTE, Reed T.; MCCULLOCH, Malcolm D. Modeling the CO2 emissions from battery electric vehicles given the power generation mixes of different countries. Energy Policy, p. 803-811, 2011. 
${ }^{4}$ de Sousa Maes, Andy, Leonardo Hoinaski, Tiago Barros Meirelles, and Rodrigo Castelan Carlson. "A methodology for high resolution vehicular emissions inventories in metropolitan areas: Evaluating the effect of automotive technologies improvement." Transportation Research Part (2019): 303-319.

${ }^{5}$ MCCARTHY, James J. et al. (Ed.). Climate change 2001: impacts, adaptation, and vulnerability: contribution of Working Group II to the third assessment report of the Intergovernmental Panel on Climate Change. Cambridge University Press, 2001.

6 MDIC. http://www.mdic.gov.br/index.php/competitividade-industrial/setor-automotivo /rota2030, Accessed on July $11^{\text {th }} 2020$. Rota 2030 - Mobilidade e Logística

7 http://www.mds.gov.br/webarquivos/publicacao/Brasil Amigo Pesso Idosa/Agenda2030 Transformando Nosso Mundo. a Agenda 2030 para o Desenvolvimento Sustentável. Recuperado em, v. 15, 2016. Accessed on July $11^{\text {th }} 2020$.

${ }^{8}$ Wang, Haikun, Lixin Fu, Xin Lin, Yu Zhou, and Jinchuan Chen. "A bottom-up methodology to estimate vehicle emissions for the Beijing urban area." Science of the total environment 407, 2009

${ }^{9}$ Meotti, Bianca, Comparação entre métodos top-down e bottom-up na estimativa de emissões veiculares 2019. https://repositorio.ufsc. br/handle/123456789/202781 Acessed on July $14^{\text {th }} 2020$.

10 VAN VUUREN, Detlef $P$. et al. Comparison of top-down and bottom-up estimates of sectoral and regional greenhouse gas emission reduction potentials. Energy policy, v. 37, n. 12, p. 5125-5139, 2009.

${ }^{11}$ WING, Ian Sue. The synthesis of bottom-up and top-down approaches to climate policy modeling: Electric power technologies and the cost of limiting US CO2 emissions. Energy Policy, v. 34, n. 18, p. 3847-3869, 2006.

${ }^{12}$ https://www.rota2030.com.br/ ROTA 2030. Accessed on July $16^{\text {th }} 2020$.

${ }^{13}$ CRUVINEL, Rodrigo Rosa da Silva; PINTO, Paulo Victor Hermetério; GRANEMANN, Sérgio Ronaldo. Mensuração econômica da emissão de $\mathrm{CO} 2$ da frota dos transportadores autônomos de cargas brasileiros. 2012. https://repositorio.unb. br/handle/10482/28656"

${ }^{14}$ SOUZA, Reinaldo Castro. Modelagem e previsão das séries de consumo de energia elétrica no Brasil com métodos de suavização exponencial de Pegels e abordagem bottom up por uso final. 2015. Tese de Doutorado. PUC-Rio.

${ }^{15}$ SOUZA Álvares Jr, O.M. e Linke, R.R.A. Metodologia Simplificada de Cálculo das Emissões de Gases do Efeito Estufa de Frotas de Veículos no Brasil. CETESB, São Paulo (2001).

${ }^{16}$ Loo, R. A Methodology for Calculating CO2 Emissions from Transport and an Evaluation of the Impact of European Union Emission Regulations. (2009) Partial fulfillment of the requirements for the degrees of Master Science in Operations Management and Logistics. Technische University Eindhoven.

${ }^{17}$ https://www.transportmeasures.org/en/wiki/manuals/all-modes/ NTM Road Procedures. Accessed on July $14^{\text {th }} 2020$

18 https://www.cedelft.eu/en/publications/832/stream-study-on-transport-emissions-of-all-modes CE Delft Organization. Accessed on July $14^{\text {th }} 2020$.

${ }^{19} \mathrm{https}: / /$ www.ifeu.de/en/ IFEU - Institut für Energie- und Umweltforschung accessed on July $14^{\text {th }} 2020$

${ }^{20} \mathrm{https}$ ://www.ecotransit.org/calculation.en. html EcoTransIT Calculation. Accessed on July $14^{\text {th }} 2020$.

${ }^{21} \mathrm{https} / / / \mathrm{trl} . c 0 . u \mathrm{k} / \mathrm{sites} /$ default/files/PPR350.pdf Creating the Future of transport. ARTEMIS. Accessed on July $14^{\text {th }} 2020$.

22 ANDRÉ, Michel. The ARTEMIS European driving cycles for measuring car pollutant emissions. Science of the total Environment, v. 334, p. 73-84, 2004.

${ }^{23} \mathrm{https://ghgprotocol.org/} \mathrm{GHC} \mathrm{Protocol.} \mathrm{Accessed} \mathrm{on} \mathrm{July} 15^{\text {th }} 2020$.

${ }^{24}$ http://ghgprotocolbrasil.com.br/?locale=pt-br GHC Protocol Brasil. Accessed on July $15^{\text {th }} 2020$. GHC Protocol. Accessed on July $15^{\text {th }} 2020$.

${ }^{25}$ https://www.epa.gov/ EPA Federal Test Procedure (FTP). Accessed on July $15^{\text {th }} 2020$.

${ }^{26}$ TSIAKMAKIS, S. et al. From NEDC to WLTP: effect on the type-approval CO2 emissions of light-duty vehicles. Publications Office of the European Union: Luxembourg, p. 50, 2017. 